\title{
Caracterização de águas residuárias de suinocultura provenientes de dois sistemas de tratamento
}

Tatiane Cristina Dal Bosco ${ }^{1}$ Natássia Jersak Cosmann²

Mariana Sbizzaro ${ }^{3}$

Ivan Taiatele Junior ${ }^{4}$

Jaqueline dos Santos Silva 5

\section{Resumo}

As águas residuárias de suinocultura apresentam características físico-químicas que variam de acordo com o sistema de higienização das baias, estádio de desenvolvimento dos animais, alimentação, condições climáticas, genética, entre outros fatores. No Brasil, o tratamento dessas águas residuárias, com elevada carga poluente, ocorre geralmente em esterqueiras e biodigestores. $\mathrm{Na}$ maioria das propriedades rurais, o destino final dos efluentes tratados é o solo. Pratica-se, portanto, o reúso de água na agricultura, que pode interferir na dinâmica de diversos poluentes no solo, como é o caso dos pesticidas. As águas residuárias apresentam-se na forma total e dissolvida, sendo esta a fração mais investigada atualmente na dinâmica desses poluentes. Neste sentido, objetivou-se utilizar a técnica de espectroscopia na região do infravermelho médio com transformada de Fourier na caracterização da matéria orgânica total e dissolvida proveniente de águas residuárias de suinocultura tratadas em biodigestor e esterqueira. Nos resultados, não foi possível observar diferenças na composição das águas residuárias pela espectroscopia infravermelha com transformada de Fourier. Entretanto, pode-se identificar a presença de materiais ainda pouco degradados e a ocorrência de grupos funcionais nitrogenados, que apontam para a liberação do nitrogênio no solo quando degradados, evidenciando o potencial de reúso dessas águas residuárias na agricultura como forma de fertirrigação.

Palavras-chave: Infravermelho. Esterqueira. Biodigestor. Efluentes.

\section{Introdução}

Marcato e Lima (2005) afirmam que o desenvolvimento da suinocultura, embora tenha proporcionado grandes benefícios à sociedade, gerou poluição ambiental em decorrência da quantidade de dejetos produzidos pelos animais, como é o caso da região norte do Rio Grande do Sul, oeste de Santa Catarina e Paraná, que já registraram contaminação das águas subterrâneas por conta da atividade. Oliveira et al. (2000) complementaram que a suinocultura é uma exploração pecuária concentradora de dejetos animais, detentores de alta carga poluidora para o solo, ar e água.

De acordo com a Associação Brasileira da Indústria Produtora e Exportadora de Carne Suína - ABIPECS (2015), 2,10 milhões de matrizes suínas industriais foram criadas no Brasil no ano de 2014, totalizando 3.471,7 mil toneladas de carne suína produzida. Desse montante, 20,04 \% do abate foi realizado no Paraná.

1 Universidade Tecnológica Federal do Paraná (UTFPR), Campus Londrina, professora doutora. Londrina, Paraná, Brasil tatianebosco@utfpr.edu.br. Av. dos Pioneiros, 3131, Jardim Morumbi, Londrina, PR. CEP: 86036-370. 
Em conformidade com Souza, Lucas Júnior e Ferreira (2005) e Deng, Chen e Mahmood (2008), a problemática ambiental da suinocultura está relacionada ao fato de que, a partir do momento em que se optou por explorações em regime de confinamento, o total de dejetos gerados, anteriormente distribuído na área destinada à exploração extensiva, ficou restrito a pequenas áreas. Além disso, houve aumento crescente da demanda por produtos de origem animal e aumento do emprego de tecnologia moderna (mecanização de operações, melhor alimentação do rebanho, controle mais eficiente de doenças, etc.), que resultou em aumento efetivo do rebanho, acompanhado por índices elevados de produtividade. Desta forma, observa-se que o problema ambiental está diretamente relacionado ao aumento da produção e ao manejo inadequado dos dejetos.

Allegretti, Schmidt e Machado (2014) avaliaram diversos indicadores ambientais em 31 propriedades suinícolas de Aratiba (RS) e identificaram o manejo de dejetos (esterqueiras subdimensionadas com tempo de retenção hidráulica insuficiente) e a análise de solo (frequência de análise baixa/ nula e mau planejamento/monitoramento da aplicação) como sendo os fatores mais críticos.

De acordo com Oliveira et al. (2000), os dejetos de animais podem, quando bem manejados, constituir-se em alternativa econômica para a propriedade rural, sem comprometimento da qualidade ambiental. Atualmente, tem-se buscado alternativas para o aproveitamento de dejeto suíno na forma de adubo orgânico ou, simplesmente, aplicando-o em solos improdutivos. Em uma granja de suínos, a quantidade diária de efluentes produzida depende, dentre outros fatores, do número e da idade dos animais e, principalmente, da quantidade de água gasta na higienização das baias. A associação desses fatores, por sua vez, definirá a concentração de sólidos na água residuária, os custos com estruturas de tratamento ou de armazenamento e a necessidade de área para recebimento dessas águas, como forma de adubação orgânica, caso seja essa a maneira escolhida para a disposição do resíduo. Hoje em dia, são recomendadas bombas de alta pressão e baixa vazão para a lavagem das baias, buscando-se economizar água nas granjas e diminuir o volume da água residuária produzida, o que é desejável; entretanto, a adoção dessa técnica na higienização implica em aumento significativo da concentração de sólidos totais da água residuária e, consequentemente, da demanda bioquímica de oxigênio (DBO).

Conforme Higarashi, Kunz e Oliveira (2007), o tratamento de dejetos suínos ainda é uma prática pouco utilizada no Brasil, em virtude dos custos e da complexidade dos processos necessários para a eficiente depuração desses efluentes, caracterizados pela alta carga poluente. Segundo Gartner e Gama (2005), entre as tecnologias empregadas no gerenciamento de dejetos suínos, destacam-se as esterqueiras, que consistem no armazenamento temporário desses resíduos para posterior aplicação ao solo (BELLI FILHO et al., 2001; SANTOS et al., 2007), e os biodigestores, que permitem a redução do potencial poluidor dos resíduos, além da geração de biogás e biofertilizante (SOUZA; LUCAS JUNIOR; FERREIRA, 2005; ANGONESE et al., 2006; OLIVEIRA; DUDA; FERNANDES, 2014).

Boa parte dos dejetos aplicados como biofertilizantes nas áreas de agricultura e pastagem passa apenas por sistema de armazenamento em esterqueiras. De acordo com Diesel, Miranda e Perdomo (2002), as esterqueiras consistem em um depósito cuja finalidade é a captação dos dejetos produzidos no sistema de criação e o armazenamento durante um determinado período, normalmente entre 4 e 6 meses, para que ocorra a fermentação anaeróbica da matéria orgânica. A preferência pelo uso de esterqueiras no manejo de dejetos suínos está associada ao relativo baixo custo de implantação e operação e à simplicidade do sistema (LORIMOR et al., 2006). Entre as desvantagens, pode-se destacar a emissão de odores e gases do efeito estufa, possibilidade de vazamentos em períodos chuvosos e diluição dos dejetos, infiltração e não separação de fases, sendo que o dejeto fica menos concentrado, requerendo maiores áreas para sua disposição final como fertilizante (DIESEL; MIRAN- 
DA; PERDOMO, 2002; HAMILTON et al., 2006). Higarashi, Kunz e Oliveira (2007) afirmaram que essa forma de manejo dos dejetos tem se mostrado inadequada, em vista da degradação ambiental observada nas regiões de grande concentração da atividade suinícola.

Diesel, Miranda e Perdomo (2002) definiram os biodigestores como “...câmaras que realizam a fermentação anaeróbia da matéria orgânica produzindo biogás e biofertilizante". Entre as vantagens do uso de biodigestores para o tratamento de dejetos, podem-se destacar a produção de biogás, a redução de odores ofensivos, a redução de carga orgânica, a redução da carga de patógenos, a meIhoria das características do biofertilizante, a redução da emissão de gases do efeito estufa durante o armazenamento e a aplicação ao solo e a possibilidade de uso para diversos tipos de resíduos (BURTON; TURNER, 2003).

Higarashi, Kunz e Oliveira (2007) explicaram que o processo de depuração mediado por microrganismos anaeróbios é o mais comumente empregado, visto que o dejeto suíno é um meio que apresenta as condições ideais para o desenvolvimento e a prevalência de tais microrganismos, pois apresenta uma grande carga de demanda bioquímica de oxigênio, o que faz com que a taxa de consumo de oxigênio seja várias vezes superior à taxa de produção, realizada pela fotossíntese e pela dissolução atmosférica superficial.

Segundo Lorimor et al. (2006), essa tecnologia, cujo tempo de detenção hidráulica normalmente é de 15 a 20 dias, promove a estabilização dos dejetos, reduz sólidos voláteis e gera metano e dióxido de carbono, geralmente na proporção de 60 - 70 \% e 30 - 40 \%, respectivamente. Konzen (2005) afirma que dejetos suínos tratados em biodigestor tiveram a carga orgânica reduzida em 78 a $80 \%$, podendo atingir, em alguns casos, até $96 \%$, quando auxiliados por agentes de biorremediação (bactérias). Além da carga orgânica, observaram-se também reduções de fósforo total (40\%), cobre total (40 \%) e zinco total (22 \%). Com a adição de bactérias, as reduções atingiram 91, 96 e 97 \%, respectivamente, para fósforo, cobre e zinco.

Observa-se, portanto, que o dejeto suíno consiste em uma mistura de água, múltiplas partículas suspensas, substâncias orgânicas e inorgânicas dissolvidas, incluindo nutrientes e contaminantes (AUST et al. , 2009). Japenga e Harmsen (1990) afirmaram que 50 \% da matéria orgânica proveniente de dejeto suíno está presente na fase líquida, que contém matéria orgânica na forma dissolvida e coloidal. Ilani, Schulz e Chefetz (2005) afirmaram que a matéria orgânica dissolvida proveniente de águas residuárias é muito heterogênea em tamanho e conteúdo. A massa molecular da matéria orgânica dissolvida varia entre menos de 500 e mais de 5000 Dalton e consiste em uma mistura de materiais húmicos, polissacarídeos, polifenóis, proteínas, lipídeos e moléculas heterogêneas. Por conta disso, os autores destacaram que é complexo determinar a estrutura química da matéria orgânica dissolvida.

Considerando a realidade brasileira das propriedades rurais quanto às formas de tratamento das águas residuárias de suinocultura (ARSs), bem como seu uso potencial como fertilizante no solo, e que a forma com que essas ARSs se apresentam (dissolvida ou total) exerce influência na dinâmica de poluentes no solo, objetivou-se utilizar a técnica de espectroscopia na região do infravermelho médio com transformada de Fourier (FTIR) na caracterização da matéria orgânica total (MOT) e dissolvida (MOD), proveniente de ARSs tratadas em biodigestor e esterqueira.

\section{Material e métodos}

As ARSs foram coletadas em duas propriedades que possuem o sistema de produção de leitões. Uma das propriedades dispõe de Biossistema Integrado para o tratamento dos dejetos suínos (Figura 1a). A coleta foi realizada no ponto em que o efluente sai do biodigestor, pois a maioria das proprieda- 
des da região estudada, que tratam os dejetos suínos com biodigestores, não possui as outras etapas de tratamento previstas no Biossistema Integrado. Assim, a coleta ocorreu no ponto do sistema que mais se aproxima da realidade dos tratamentos de dejetos suínos da região.

A ARS de esterqueira foi coletada em propriedade rural onde os dejetos suínos são tratados em três lagoas de estabilização em série. A coleta ocorreu na saída do efluente da terceira lagoa (Figura 1b).
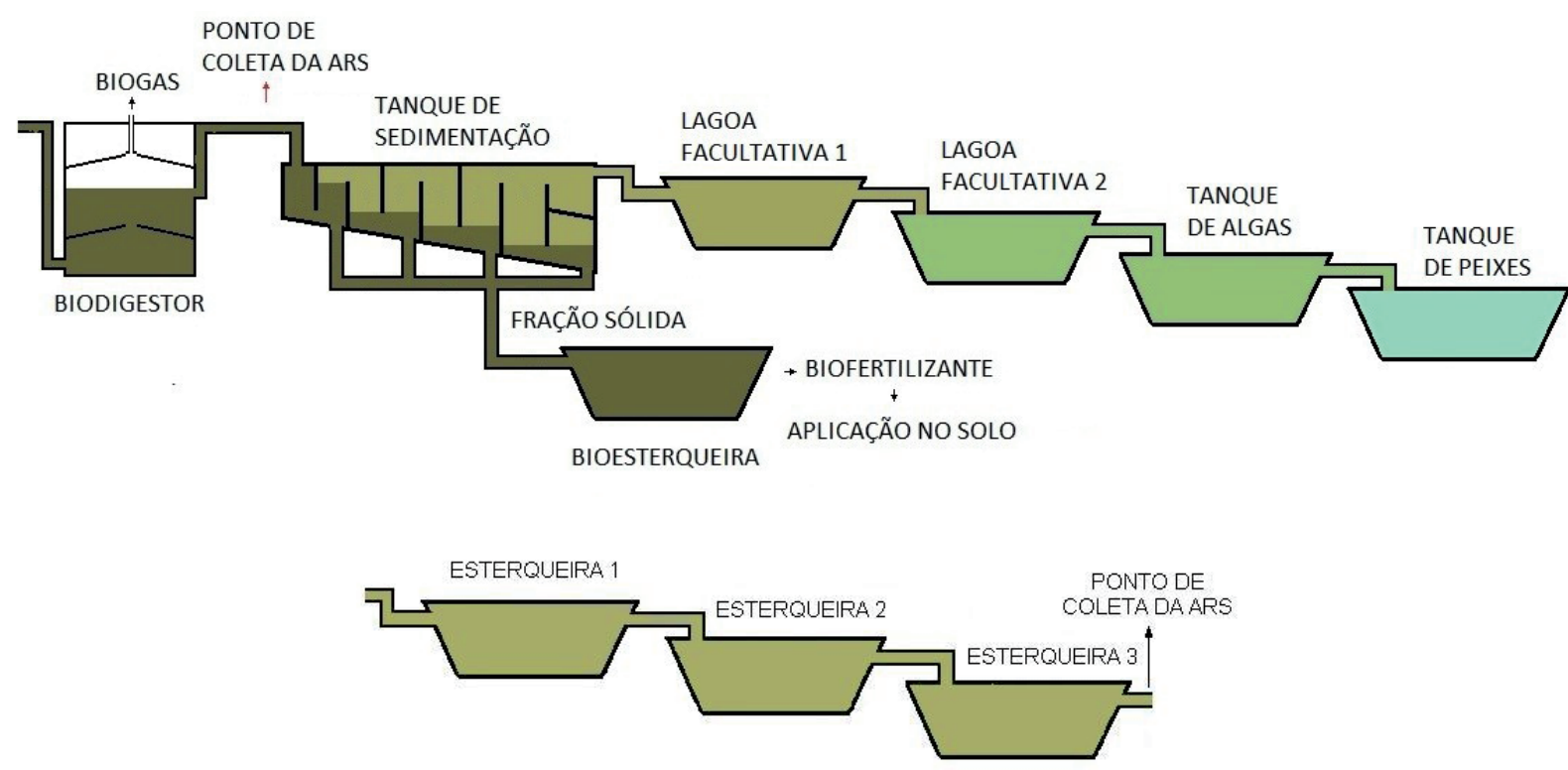

Figura 1. Esquema representativo do ponto de coleta da água residuária de suinocultura na propriedade que dispõe de Biossistema Integrado (a) e na propriedade que dispõe de esterqueiras (b) para o gerenciamento dos dejetos.

Fonte: Elaboração dos autores.

A MOT consistiu na ARS da forma como foi coletada e a MOD foi extraída das ARSs a partir da adaptação da metodologia descrita por Zhaohai et al. (2008). Na extração da MOD foram utilizados métodos de centrifugação e filtração. Inicialmente realizou-se a centrifugação a 3200 rpm (2474 g), por 15 minutos e, em seguida, o sobrenadante foi filtrado em membrana de acetato de celulose de 0,45 $\mu \mathrm{m}$ de porosidade. Após a filtração, o material foi congelado.

Nas ARSs (MOD e MOT) determinaram-se: pH, Condutividade Elétrica (C.E.), Demanda Química de Oxigênio (DQO), Carbono Orgânico Total (COT), Nitrogênio total $\left(\mathrm{N}_{\text {total }}\right)$, Nitrogênio amoniacal $\left(\mathrm{N}_{\text {amoniacal }}\right)$, Nitrogênio inorgânico $\left(\mathrm{N}_{\text {inorgânico }}\right)$, Nitrogênio orgânico $\left(\mathrm{N}_{\text {orgânico }}\right)$, Nitrito + Nitrato $\left(\mathrm{NO}_{2}+\mathrm{NO}_{3}\right)$, Fósforo (P), Potássio (K), Sódio (Na), Cálcio (Ca), Magnésio (Mg), Enxofre (S), Boro (B), Manganês (Mn), Ferro (Fe), Cobre (Cu), Zinco (Zn), Sólidos totais (ST), Sólidos fixos (SF) e Sólidos voláteis (SV), de acordo com metodologias descritas em APHA, AWWA e WEF (2012). O conteúdo de COT foi analisado em determinador de carbono orgânico total (TOC), modelo TOC-V CPH, da marca Shimadzu ${ }^{\circledR}$.

Caracterizaram-se as ARSs na forma de MOT e MOD por espectroscopia na região do infravermelho médio com transformada de Fourier (FTIR) em equipamento que dispõe de acessório de reflexão total atenuada (ATR - attenuated total reflection). Utilizou-se de um espectrofotômetro de FTIR, Jasco $^{\circledR} 4200$, e os espectros das amostras liofilizadas foram obtidos a partir de 64 acumulações, com resolução de $4 \mathrm{~cm}^{-1}$, na faixa de $4.000-500 \mathrm{~cm}^{-1}$. 
As atribuições orgânicas para as bandas observadas nos espectros de FTIR foram feitas pelo método comparativo com dados disponíveis em Pavia, Lampman e Kriz (2001) e Silverstein, Webster e Kiemle (2007) e buscaram-se trabalhos da área para confirmar as associações, que foram apresentados ao longo da discussão dos resultados obtidos.

\section{Resultados e discussão}

As características físico-químicas das ARSs tratadas em biodigestor e esterqueiras na forma dissolvida e total são apresentadas na Tabela 1.

Tabela 1. Caracterização físico-química das águas residuárias de suinocultura.

\begin{tabular}{|c|c|c|c|c|c|}
\hline Parâmetros & Unidade & МОТ-В & MOD-B & MOT-E & MOD-E \\
\hline $\mathrm{pH}_{(\mathrm{CaCl} / 2)}$ & - & 7,15 & 8,27 & 7,20 & 8,07 \\
\hline C.E. & $\mu \mathrm{S} \mathrm{cm} \mathrm{cm}^{-1}$ & 6810,00 & 5820,00 & 6990,00 & 6270,00 \\
\hline DQO & & 4830,00 & 1539,00 & 2154,00 & 1405,00 \\
\hline COT & & 967,00 & 355,60 & 547,30 & 255,40 \\
\hline$N_{\text {total }}$ & & 1190,00 & 905,30 & 967,90 & 863,30 \\
\hline $\mathrm{N}_{\text {amoniacal }}$ & & 980,00 & 812,00 & 884,80 & 812,00 \\
\hline $\mathrm{N}_{\text {inorgânico }}$ & & 1092,00 & 868,00 & 921,20 & 840,00 \\
\hline $\mathrm{N}_{\text {orgânico }}$ & & 98,00 & 37,30 & 46,70 & 23,30 \\
\hline $\mathrm{NO}_{2}+\mathrm{NO}_{3}$ & & 112,00 & 56,00 & 36,40 & 28,00 \\
\hline$P$ & & 61,38 & 37,30 & 52,91 & 25,79 \\
\hline K & & 458,50 & 425,00 & 524,00 & 463,50 \\
\hline $\mathrm{Na}$ & & 158,30 & 150,00 & 183,30 & 170,80 \\
\hline $\mathrm{Ca}$ & $\mathrm{mg} \mathrm{L}^{-1}$ & 122,50 & 70,50 & 114,00 & 38,00 \\
\hline Mg & & 28,00 & 19,00 & 40,00 & 18,00 \\
\hline $\mathrm{S}$ & & 37,57 & 21,62 & 31,35 & 23,24 \\
\hline B & & 1,10 & 0,76 & 0,93 & 0,47 \\
\hline $\mathrm{Mn}$ & & 0,93 & 0,21 & 0,61 & 0,14 \\
\hline $\mathrm{Fe}$ & & 2,15 & 1,39 & 1,61 & 1,17 \\
\hline $\mathrm{Cu}$ & & 1,16 & 0,20 & 0,55 & 0,18 \\
\hline $\mathrm{Zn}$ & & 1,70 & 0,73 & 1,77 & 0,30 \\
\hline ST & & 3860,00 & 2510,00 & 3193,00 & 2104,00 \\
\hline SF & & 2106,00 & 1674,00 & 2 129,00 & 1457,00 \\
\hline SV & & 1755,00 & 837,00 & 1064,00 & 647,00 \\
\hline
\end{tabular}

Fonte: Elaboração dos autores.

Verifica-se que a MOD apresentou concentrações menores em relação à MOT para todos os parâmetros analisados (Tabela 1). Esse comportamento está associado ao fato de os sólidos em suspensão e parte dos coloidais serem retidos no processo de filtração, o que diminui a concentração da carga orgânica, nutrientes e sólidos (Figura 2). A carga orgânica da ARS tratada em biodigestor foi maior do que a ARS proveniente da esterqueira. Provável explicação para esse resultado é que nas lagoas de tratamento ocorre a sedimentação parcial de sólidos suspensos sedimentáveis, que também possuem carga orgânica, enquanto que no biodigestor essa fração não sofre decanta- 
ção no interior do reator (HAMILTON et al., 2006). Outra causa é a possível diluição da ARS oriunda de esterqueiras, visto que são sistemas abertos e sujeitos às influências de precipitações. Outro fator que pode estar associado é que a coleta ocorreu na saída da terceira lagoa. Esse tratamento em série pode ter reduzido a carga orgânica da ARS.

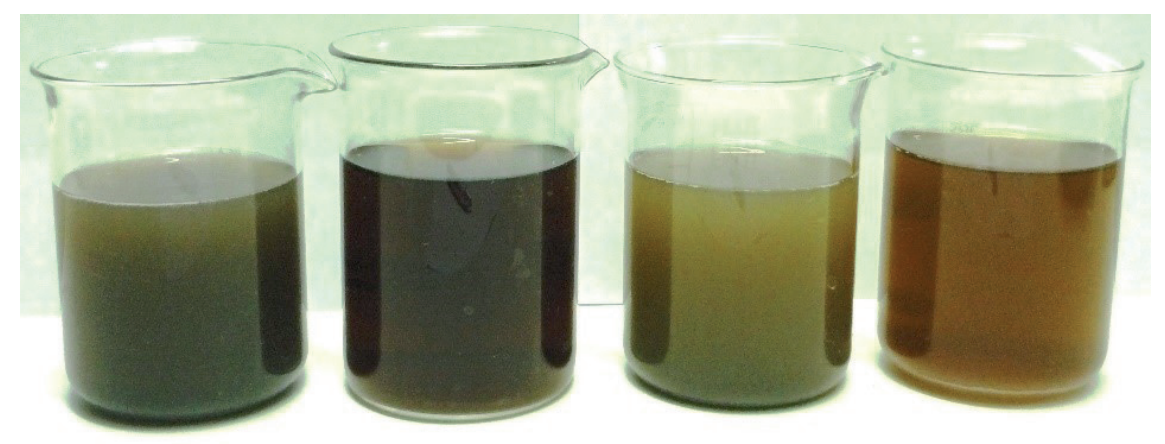

Figura 2. Aspecto visual das águas residuárias de suinocultura. Fonte: Elaboração dos autores.

Pela técnica de infravermelho, nota-se semelhança entre MOT-B, MOD-B, MOT-E e MOD-E, do ponto de vista de composição de grupos orgânicos (Figura 3a e 3b). Não é possível observar diferenças entre os espectros de MOT e MOD e tão pouco entre as diferentes ARSs utilizadas.

Observa-se (Figura 3) que, acima de $3000 \mathrm{~cm}^{-1}$, a banda refere-se ao estiramento $\mathrm{C}-\mathrm{H}$ de compostos aromáticos (FERREIRA, 2008). A faixa de 3000 e $2500 \mathrm{~cm}^{-1}$ é típica de bandas relacionadas aos estiramentos C-H de compostos alifáticos (DIAS et al., 2009). Dias et al. (2009) destacaram que a banda de absorção característica dos grupos metil e metileno $\left(\mathrm{CH}_{2} \mathrm{e} \mathrm{CH}_{3}\right)$ ocorre em comprimentos de onda de 2940 - $2840 \mathrm{~cm}^{-1}$. A banda de $1600 \mathrm{~cm}^{-1}$ indica a presença de grupos carbonílicos referentes à amida, caracterizando a presença de compostos nitrogenados na ARS. Observa-se banda pouco pronunciada na região de $1494 \mathrm{~cm}^{-1}$. Freixo, Canellas e Machado (2002) associaram essa região à presença de ligação $\mathrm{C}=\mathrm{C}$ de aromáticos, característica inerente aos compostos lábeis da matéria orgânica. Stevenson (1994) atribuiu bandas nas regiões de 2920 - 2850 e $1450 \mathrm{~cm}^{-1}$ aos estiramentos e deformação $\mathrm{C}-\mathrm{H}$, respectivamente, de materiais alifáticos ricos em compostos não humificados, como é o caso dos carboidratos. Ilani, Schulz e Chefetz (2005) associaram a região compreendida entre 1240 - $1260 \mathrm{~cm}^{-1}$ à presença de ligações carbono-carbono de compostos aromáticos. Na região entre 1100 e $1000 \mathrm{~cm}^{-1}$ pode-se ter estiramento C-O de polissacarídeos (ILANI; SCHULZ; CHEFETZ, 2005; DIAS et al., 2009).

Kuroki et al. (2009), que estudaram as características da ARS submetida ao processo de biodigestão anaeróbia, observaram que a intensidade das bandas registradas pelo infravermelho nessa região é constante durante todo o processo de tratamento, tendo em vista que muitos polissacarídeos apresentam alta resistência à degradação biológica. A região abaixo de $1000 \mathrm{~cm}^{-1}$ geralmente pode ser atribuída à impressão digital de substâncias aromáticas e a compostos silicatados (FERREIRA, 2008; KUROKI et al., 2009). 
(a)

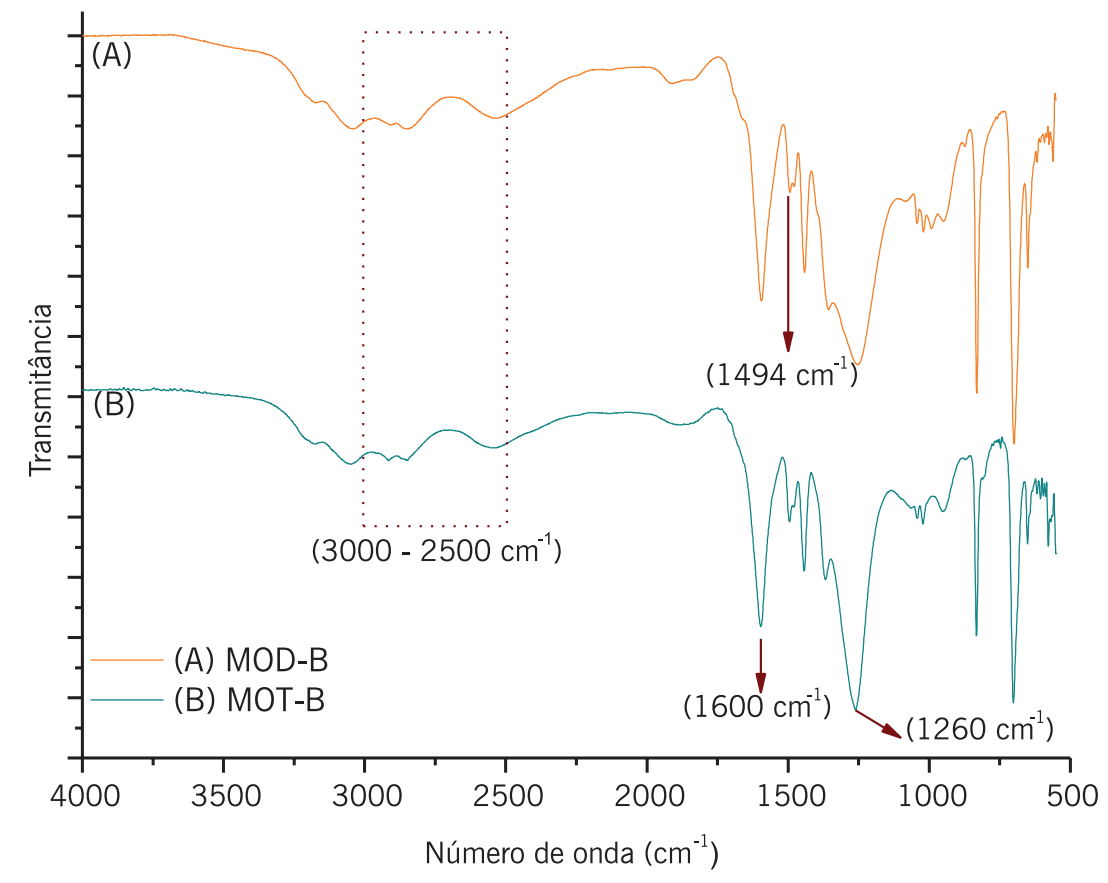

(b)

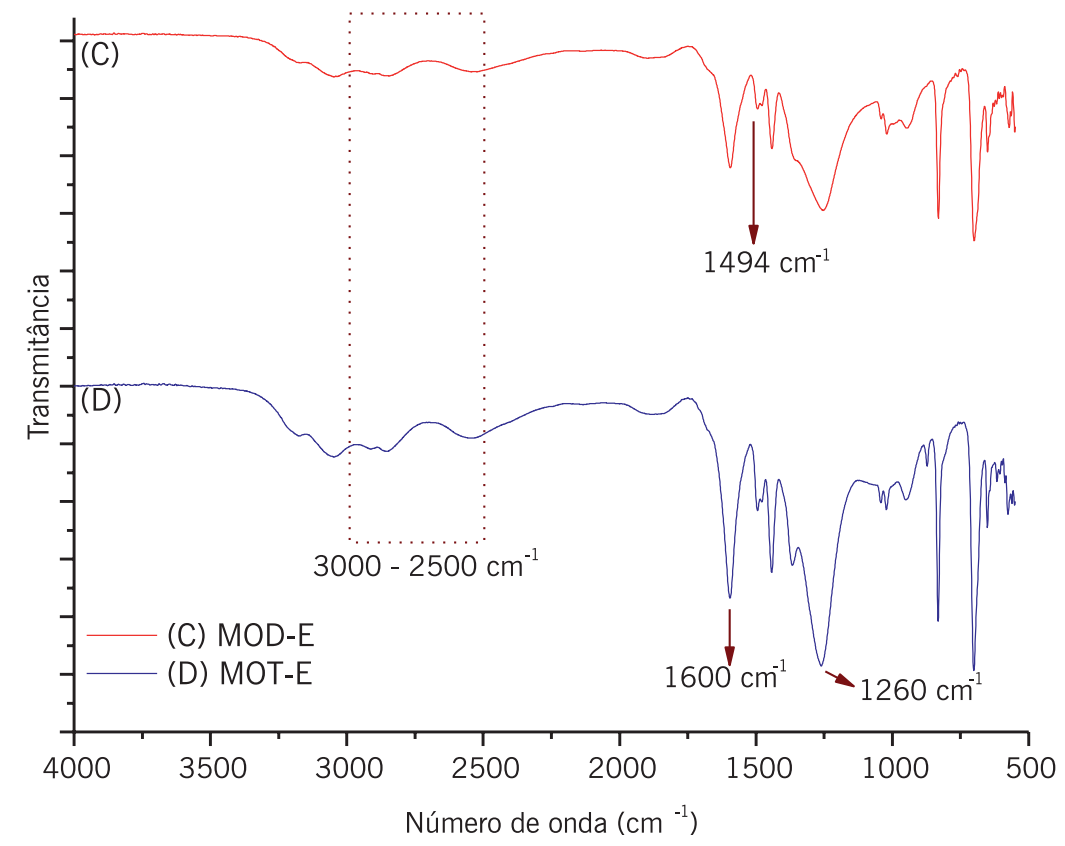

Figura 3. Espectros de FTIR das águas residuárias de suinocultura tratadas em biodigestor (a) e esterqueira (b). Fonte: Elaboração dos autores.

\section{Conclusões}

A espectroscopia infravermelha com transformada de Fourier não permitiu a diferenciação entre as variações de tratamentos e formas das águas residuárias de suinocultura. No entanto, possibilitou identificar a presença de materiais ainda pouco degradados. A presença de grupos funcionais nitrogenados aponta para a liberação do nitrogênio no solo quando degradados, evidenciando o potencial de reúso dessas águas residuárias na agricultura como forma de fertirrigação. 


\title{
Characterization of swine wastewater derived from two treatment systems
}

\begin{abstract}
The swine wastewater have physicochemical characteristics that vary according to the system of cleaning the stalls, stage of development of animals, food, weather, genetics, among other factors. In Brazil, the treatment of wastewater with high pollution load usually occurs in digesters and manure lagoon. In the vast majority of farms, the final destination of treated effluent is the soil. Therefore, the reuse of water in agriculture is carried out, what can interfere in the dynamics of various pollutants in the soil, such as pesticides. Wastewaters are presented as total and dissolved, and this fraction is more investigated in the current dynamic of these pollutants. Thus, it was used the technique of spectroscopy in the infrared Fourier transform spectroscopy to characterize the total and dissolved organic matter from swine wastewater treated in biodigester and manure lagoon. In the results, it was not possible to observe differences in the composition of the wastewater by infrared spectroscopy with Fourier transform. However, one can identify the presence of poorly degraded materials and the occurrence of nitrogen functional groups, which point to the release of nitrogen in the soil when degraded, indicating the potential for reuse of this wastewater in agriculture as a means of fertigation.
\end{abstract}

Keywords: Infrared. Manure lagoon. Biodigester. Effluent.

\section{Referências}

ALLEGRETTI, G.; SCHMIDT, V.; MACHADO, J. A. D. Sustentabilidade na suinocultura de terminação: indicadores ambientais de desempenho em um município gaucho. Ciência e Natura, Santa Maria, v. 36 , p. 677-684, 2014.

AMERICAN PUBLIC HEALTH ASSOCIATION - APHA; AWWA, WEF. Standard methods for the examination of water and wastewater. 22 ed. Washington: American Public Health Association, 2012.

ANGONESE, A. R.; CAMPOS, A. T.; ZACARKIM, C. E.; MATSUO, M. S.; CUNHA, F. Eficiência energética de sistema de produção de suínos com tratamento dos resíduos em biodigestor. Revista Brasileira de Engenharia Agrícola e Ambiental, Campina Grande, v. 10, n. 3, p. 745-750, 2006.

ASSOCIAÇÃO BRASILEIRA DA INDÚSTRIA PRODUTORA E EXPORTADORA DE CARNE SUÍNA (ABIPECS). Relatório Anual 2015. Disponível em: < http://abpa-br.com.br/files/publicacoes/c59411a243d6dab1da8e605be58348ac.pdf. Acesso em: 04 ago. 2016.

AUST, M. O.; THIELE-BRUHN, S.; ECKHARDT, K. U.; LEINWEBER, P. Composition of organic matter in particle size fractionated pig slurry. Bioresource Technology, Oxford, v. 100, n. 23, p. 5736-5743, 2009.

BELLI FILHO, P.; CASTILHOS JR.; A. B. de.; COSTA, R. H. R. da.; SOARES, S. R.; PERDOMO, C. C. Tecnologias para o tratamento de dejetos suínos. Revista Brasileira de Engenharia Agrícola e Ambiental, Campina Grande, v.5, n.1, p.166-170, 2001.

BURTON, C. H.; TURNER, C. Anaerobic treatment options for animal manures. In: Manure

Management: Treatment Strategies for Sustainable Agriculture. UK: Bedford, 2003. p. 273-320. 
DENG, L.; CHEN, Z.; MAHMOOD, Q. Improvement in post-treatment of digested swine wastewater. Bioresource Technology, Oxford, v. 99, n. 8, p. 3136-3145, 2008.

DIAS, B. O.; SILVA, C. A.; SOARES, E. M. B.; BETTIOL, W.; GUERREIRO, M. C.; BELIZÁRIO, M. H. Infravermelho na caracterização de ácidos húmicos de Latossolo sob efeito de uso contínuo de lodo de esgoto. Revista Brasileira de Ciência do Solo, Viçosa, v. 33, n. 4, p. 885-894, 2009.

DIESEL, R.; MIRANDA, C. R.; PERDOMO, C. C. Coletânea de tecnologias sobre dejetos suínos. Embrapa Suínos e Aves e Extensão. EMATER/RS, ano 10, agosto/2002. (Boletim Informativo de Pesquisa n. 14).

FERREIRA, F. P. Caracterização das substâncias húmicas extradídas do solo do manguezal de Pai Matos (Cananéia, SP, BR) e de marismas da Espanha (Galícia e Valência). 2008. 125 f. Tese de Doutorado - Programa de Pós-Graduação em Agronomia - Escola Superior de Agricultura "Luiz de Queiróz" - Universidade de São Paulo, Piracicaba, 2008.

FREIXO, A. A.; CANELLAS, L. P.; MACHADO, P. L. O. A. Propriedades espectrais da matéria orgânica leve-livre e leve intra-agregado de dois Latossolos sob plantio direto e preparo convencional. Revista Brasileira de Ciência do Solo, Viçosa, v. 26, n. 2, p. 445-453, 2002.

GARTNER, I. R.; GAMA, M. L. S. Avaliação multicriterial dos impactos ambientais da suinocultura no Distrito Federal: um estudo de caso. Organizações Rurais Agroindustriais, Lavras, v. 7, n. 2, p. 148-161, 2005.

HAMILTON, D. W.; FATHEPURE, B.; FULHAGE, C. D.; CLARKSON, W.; LALMAN, J. Treatment laggons for animal agriculture. In: RICE, J. M.; CALDWELL, D. F.; HUMENIK, F. J. (Eds). Animal agriculture and the environmental: National Center for Manure \& Animal waste management. USA: American Society of Agriculture and Biological Engineers, p. 547-573. 2006.

HIGARASHI, M. M.; KUNZ, A.; OLIVEIRA, P. A. V. de. Redução da carga poluente: Sistemas de tratamento. In: SEGANFREDO, M. A. (Ed.). Gestão Ambiental na Suinocultura. Brasília: Embrapa Informação Tecnológica, 2007. Cap. 5, p. 121-148.

ILANI, T.; SCHULZ, E.; CHEFETZ, B. Interactions of organic compounds with wastewater dissolved organic matter: role of hydrophobic fractions. Journal of Environmental Quality, Madison, v. 34, n. 2, p. 552-562, 2005.

JAPENGA, J.; HARMSEN, K. Determination of mass balances and ionic balances in animal manure. Netherlands Journal of Agricultural Science, Wageningen, v. 38, n. 3, p. 353-367, 1990.

KONZEN, E. A. Dejetos de suínos fermentados em biodigestores e seu impacto ambiental como insumo agrícola. In: SIMPÓSIO GOIANO DE AVICULTURA, 6.; e SIMPÓSIO GOIANO DE SUINOCULTURA - AVESUI Centro-Oeste, 2.; 2005, Goiânia. Anais... Goiânia: CNPSA, 2005. p. 56-64.

KUROKI, V.; ALMEIDA, L. F.; NOVAES, A. P.; MAGNONI JR, L.; NOGUEIRA, A. R. A.; SOUZA, G. B.; SILVA, W. T. L. Avaliação físico-química de efluente gerado em biodigestor anaeróbio visando aplicação como fertilizante agrícola. In: SIMPÓSIO INTERNACIONAL SOBRE GERENCIAMENTO DE RESÍDUOS DE ANIMAIS: USO DOS RESÍDUOS DA PRODUÇÃO ANIMAL COMO FERTILIZANTE, 1, 2009, Florianópolis, Anais.... Florianópolis: UFSC, 2009. p. 452-457. CD-ROOM. 
LORIMOR, J.; FULHAGE, C.; ZHANG, R.; FUNK, T.; SHEFFIELD, R.; SHEPPARD, D. C.; NEWTON, G. L. Manure Management Strategies and Technologies. In: RICE, J. M.; CALDWELL, D. F.; HUMENIK, F. J. (Eds). Animal agriculture and the environmental: National Center for Manure \& Animal waste management. USA: American Society of Agriculture and Biological Engineers, 2006. p. 409-434.

MARCATO, S. M.; LIMA, G. J. M. M. de. Efeito da restrição alimentar como redutor de poder poluente dos dejetos de suínos. Revista Brasileira de Zootecnia, Viçosa, v. 34, n. 3, p. 855-863, 2005.

OLIVEIRA, R. A.; CAMPELO, P. L. G.; MATOS, A. T. MATINEZ, M. A. CECON, P. R. Influência da aplicação de águas residuárias de suinocultura na capacidade de infiltração de um solo podzólico vermelho-amarelo. Revista Brasileira de Engenharia Agrícola e Ambiental, Campina Grande, v. 4, n. 2, p. 263-267, 2000.

OLIVEIRA, R. A.; DUDA, R. M.; FERNANDES, G. F. R. Reator anaeróbio compartimentado para o tratamento de águas residuárias de suinocultura. Revista Engenharia Sanitária e Ambiental, v. 19, n. 4, p.383-391, 2014.

PAVIA, D. L.; LAMPMAN, G. M.; KRIJ, J.; Introduction to Spectroscopy - A Guide for Students of Organic Chemistry. Cruzda: Brooks, Cole Thonson Learning, 2001. 579p.

SANTOS, M. A. A. dos; SCHMIDT, V.; BITENCOURT, V. C.; MAROSO, M. T. D. Esterqueiras: avaliação físico-química e microbiológica do dejeto suíno armazenado. Engenharia Agrícola, Jaboticabal, v. 27, n. 2, p. 537-543, 2007.

SILVERSTEIN, R. M.; WEBSTER, F. X.; KIEMLE, D. J. Identificação espectrométrica de compostos orgânicos. 7. ed. Rio de Janeiro: LTC, 2007. 490p.

SOUZA, C. F.; LUCAS JUNIOR, J.; FERREIRA, W. P. M. Biodigestão anaeróbia de dejetos de suínos sob efeito de três temperaturas e dois níveis de agitação do substrato: considerações sobre a partida. Engenharia Agrícola, Jaboticabal, v. 25, n. 2, p. 530-539. mai./ago.; 2005.

STEVENSON, F. J. Humus chemistry: genesis, composition, reactions. 2.ed. New York: John Wiley \& Sons, 1994. 496p.

ZHAOHAI, S.; LI, M.; QIMING, X.; YIJUN Y.; HUI, L.; HONGXIA, Y. Effects of dissolved organic matter from sewage sludge on sorption of tetrabromobisphenol $A$ by soils. Journal of Environmental Sciences, Mansoura, v. 20, n. 9, p. 1075-1081, 2008.

\section{Histórico editorial}

Submetido em: 23/06/2015

Aceito em: 03/11/2015 